\title{
Newer Technologies, Better Healthcare
}

\author{
L De Stefano*1,2, I Rea ${ }^{1}$, P Dardano ${ }^{1}$, M Balestrieri ${ }^{3}$, G Palmieriं ${ }^{2,3}$, B Agrillo ${ }^{2}$, M Terracciano ${ }^{2}$, M Battisti ${ }^{2}$, \\ A Cammarano ${ }^{2}$ and L Nicolais ${ }^{2}$ \\ ${ }^{1}$ Institute for Microelectronics and Microsystems, Italy
}

${ }^{2}$ Materias Srl, Corso N. Protopisani, Napoli

${ }^{3}$ Institute for Bioresources and Biosciences, Italy

*Corresponding author: Luca De Stefano, Senior scientist, Institute for Microelectronics and Microsystems, Italy

\begin{tabular}{|c|c|}
\hline ARTICLE INFO & ABSTRACT \\
\hline & Just like any other field of human knowledge application, also Medicine is going Nano. \\
\hline Published: 慧 February 15, 2019 & $\begin{array}{l}\text { The keywords announcing the dawn of a new era in the general area of healthcare are } \\
\text { personalized therapies, point of care, Nano vectors, microneedles, theranostics. These in- }\end{array}$ \\
\hline $\begin{array}{l}\text { Citation: L De Stefano, I Rea, P } \\
\text { Dardano, M Balestrieri, G Palmieri, B } \\
\text { Agrillo, M Terracciano, M Battisti, A } \\
\text { Cammarano, L Nicolais. Newer Tech- } \\
\text { nologies, Better Healthcare. Biomed }\end{array}$ & $\begin{array}{l}\text { novative instruments will fight against old and new plagues, such as silent cancers, car- } \\
\text { dio-pathologies, degenerative diseases, resistant infections. The new weapons available to } \\
\text { medical doctors are the result of highly interdisciplinary collaborations between biologist, } \\
\text { chemists, physicists and engineers, stating the supremacy of cross fertilization of culture } \\
\text { over isolated box of expertise. }\end{array}$ \\
\hline
\end{tabular}

Sci \& Tech Res 14(4)-2019. BISTR. MS.ID.002585.

\section{Introduction}

Modern approach to healthcare is largely mediated by economic factors since public health budget is in constant growth in all the Western nations. The aging of the population also increases the minimum needs and the hospital admissions rate [1]. Many possible solutions have been proposed to face this big problem from every possible side: for example, food awareness campaigns, mass vaccinations, diagnostic screening by age group. Every large scale initiative sees its effectiveness greatly reduced by the intrinsic limits of traditional medicine, based almost exclusively on clinical practice supported by statistical studies and on pharmacological chemistry [2]. The next revolution in medicine, and more generally speaking in healthcare, will come from innovative technologies acquired from very different field of applications, such as large electronic consumer and telecommunication, and adapted to specific problems [3]. In particular, micro- and nanotechnologies, i.e. systems and devices having dimensions under 10-6 m, are driving the development of new products more performing than the existing ones. Scaling down the size of common materials, both the organics and the inorganics, it is not only matter of fabrication ability, but it opens the way to a completely diverse world where things behave different [4]. In some cases, the matter properties drastically change on the nanoscale. Crystalline silicon, the basic material in electronic, is not light emitting and can cause silicosis, a pulmonary disease, whereas its nanostructured counterpart, the porous silicon, is photoluminescent and completely biodegradable; carbon is highly insulating, since it has a very large bandgap, while carbon nanotubes and graphene are highly conductive; and the list of examples could continue for a long. In other cases, such as the one of popular microfluidics, geometrical features matter more than bulk properties.

As a matter of fact, when linear dimension (L) decreases, surface interaction scale more slowly (as L-2) with respect to volume (as L-3), so that surfaces are more important than volume. There is also another big obstacle that delays the advancement of more efficient practices in medicine due to the intrinsic difficulty of translating laboratory science into industrial production. Most of the scientific discoveries found in the academic habit is lost in a "Death Valley" before industry could get advantages from them. In this view, technology transfer companies play a strategic role in overcoming the gap between scientific research and industrial development. In South Italy, Materia's Srl is one of the most active start-up company highly specialized in technology transfer. In this 
perspective paper, we will focus on two specific systems, developed in collaboration with academic institutions, that are explicative of brand new technologies applied to human healthcare, the polymeric microneedles and the peptide functionalized nanoparticles.

\section{Observations}

Drug delivery is a hot topic in translational medicine, since it involves pharmacokinetics and pharmacodynamics, which are related to when, where and how an active molecule goes and works in the human body. Moreover, drug delivery can be systemic, i.e. drug injected in blood, or local, when the drug is delivered in a specific site. New technologies are available for both methodologies $[5,6]$. The dermis is the thickest component of the skin, up to $4 \mathrm{~mm}$ in depth. Its upper layer, the $100-200 \mu$ m thick papillary dermis, consists of thin collagen bundles, elastin fibers, fibrocytes. There is also water, electrolytes, plasma proteins and polysaccharidespolypeptide complexes. Below this layer is the reticular dermis, made up of thick collagen bundles and coarse elastic fibers. Although the stratum corneum (SC) is the major contributor to the barrier properties of the skin. The thickness of the SC varies throughout the body. In the palms of the hands and the soles of the feet (sometimes knees, elbows, knuckles,) this layer is stabilized and built by the stratum lucidum (clear phase) which allows the cells to concentrate keratin and toughen them before they rise into a typically thicker, more cohesive SC. In general, the stratum corneum has a thickness between 10 and $40 \mu \mathrm{m}$. Only compounds which are able to get into the SC, diffuse through living epidermis and pass through the upper part of the papillary dermis has the potential to reach circulation and exhibit systemic effects [7].

Biodegradable and biocompatible MNs could be used for local drug delivery [8]. Materia's Srl has patented two technologies for fabricating MN by using a photolithographic approach. These devices can be added with a porous silicon free-standing membrane, using, for example, polyethylene glycol (PEG) or other biodegradable polymers and a commercial photo-catalyzer $[9,10]$. In Figure 1 are reported the sketch and the optical images of pyramidal MN, conical hollow MN and a detailed micro-photo of a hollow MN realized by a scanning electron microscope. Transdermal MNs create micron sized pores in the skin to enhance delivery of the drug across the skin. MN are ideal for patient adherence as they do not stimulate nerves that are associated with pain. MN improve patient compliance as patient with needle phobia will be more likely to apply the patch because of its painlessness. Additionally, patients can administer the drug by themselves. The porous MNs not only increase the storage of a relevant amount of the drug, but also offers a continuous, naked-eye monitoring of the drug delivery process.
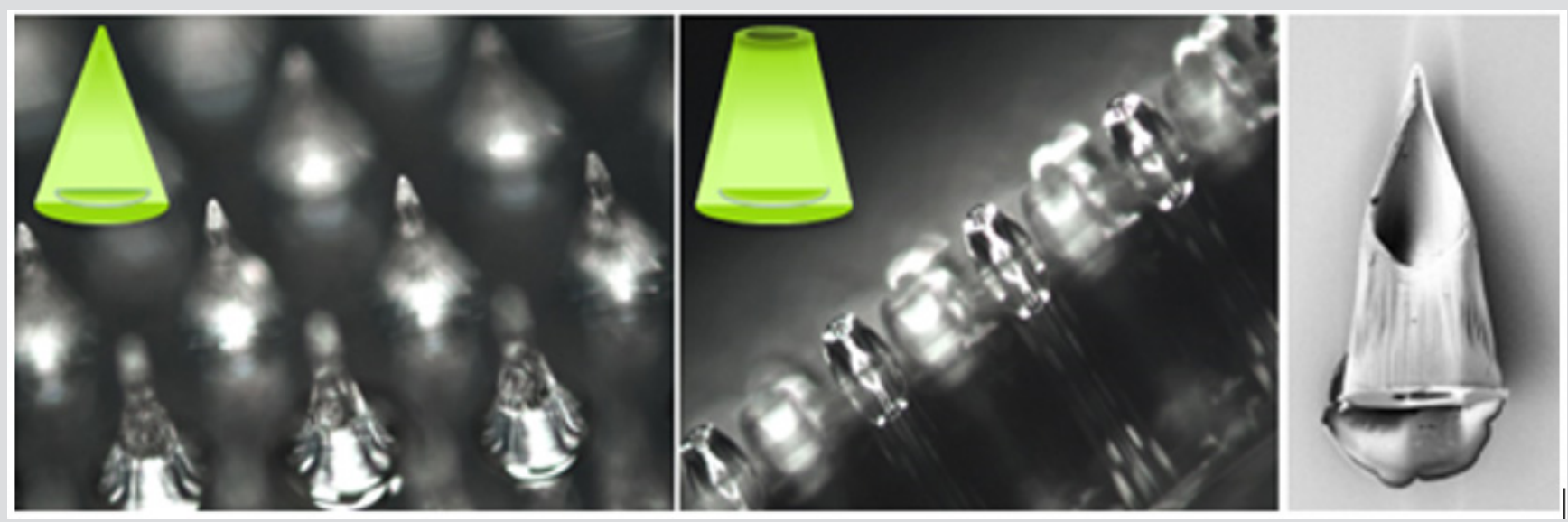

Figure 1: Schematics and images of polymeric MN: pyramidal shaped, conical shaped and hollow. Last image is highly detailed image of hollow MN realized by a scanning electron microscope.

Polymeric hollow MNs (HMNs) could be used for the transdermal administration of active molecules and/or for the sampling of biological fluids. Pressure, and thereby flow rate, can be changed in HMNs for a rapid bolus injection, a slow infusion or a varied delivery rate. HMNs can also be used to administer a larger dose of drug solution. MNs are mechanically strong to penetrate skin, increasing the permeability of encapsulated drug through skin. Moreover, the drug release from MNs, can be thermally activated, through the variation of the permeability. The drug diffuses from the drug reservoir (MNs back-plate) via the MNs into the skin. Systemic delivery of drugs suffers, both in case of oral administration or of blood injection, strongly suffers from human body response. The pills ingested are seriously degraded by acid environment in the stomach and the efficacy of the active principle contained in the pills depends on enteric absorption. On the other hand, molecules in the blood must face more than 8000 proteins, enzymes and other components that easily neutralize the active substance. Nano-formulation of drugs is the technological way to overcome these intrinsic difficulties. In this field, Materia's Srl has patented one Nano-system of proved antimicrobial activity [11]. The nanocomplex is made of a small synthetic peptide, derived from bovine immune system, covalently bioconjugate to small hybrid 
gold nanoparticles [12]. This Nano systems has been proved to be strongly active against human pathogens in very low concentration, i.e. in the sub micromolar range $[13,14]$.

\section{Discussion}

Nanomedicine has been recently defined as a specific subset of nanotechnology, in particular, as the detection, repair, construction and control of human biological systems at the molecular level, using engineered nanodevices and nanostructures. The two examples exploited by Materia's Srl by developing two industrial products from laboratory proof-of concept to pre-production level, clearly demonstrated that the next future of medicine, and in a larger view also of the entire healthcare system, will be based on the application of innovative technologies to specific biological and medical problems. Nanotechnologies are changing the world as we are used to know it, favoring the large distribution of diagnostic, therapeutic and life saving devices, with performances comparable to those of laboratory instrumentation. The health market requirements push for faster and newer class of devices based on nanotechnologies that are continuously developed in academic laboratories all over the world. This is the reason why there is also the need of technology transfer societies which help innovation to go from laboratories up to the final users, increasing the quality of life of everyone.

\section{Acknowledgement}

Authors would like to thank all the people working in their laboratories for finite period of time, such as fellowship and $\mathrm{PhD}$ students without which much of what was accomplished would not have been possible.

\section{References}

1. Henderson S, Horne M, Hills R, Kendall E (2018) Cultural competence in healthcare in the community: A concept analysis. Health \& social care in the community 26(4): 590-603.

2. Rich CR, Singleton JK, Wadhwa SS (2018) Sustainability for healthcare management: a leadership imperative. In: Rich CR, Singleton JK, Wadhwa SS (eds.) ( $\left.2^{\text {nd }} E d n\right)$ Routledge ed ,New York ,USA.

\section{ISSN: 2574-1241}

DOI: 10.26717.BJSTR.2019.14.002585

Luca De Stefano. Biomed J Sci \& Tech Res

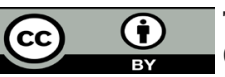

This work is licensed under Creative

Commons Attribution 4.0 License

Submission Link: https://biomedres.us/submit-manuscript.php
3. Rea I, Terracciano M, De Stefano L (2017) Synthetic vs Natural: diatom bioderived porous materials for next generation of healthcare nanodevices Adv. Healthcare Mater 6(3): 1601125.

4. R Perumal, S Casale, L De Stefano, J Spadavecchia (2017) Synthesis and characterization of Ag-Protoporphyrin nano-structures using mixed copolymer method. Frontiers in Laboratory Medicine 1(2): 49-54.

5. L De Stefano, I Rea, P Dardano, L Nicolais (2017) Dispositivo per la somministrazione transdermica di molecole attive, usi di tale dispositivo e metodi di produzione di tale dispositivo e di relativi component.

6. M Balestrieri, G Palmieri, G Neglia, A Anastasio, F Capuano, et al. Peptidi antimicrobici.

7. A Caliò, P Dardano, V Di Palma, MF Bevilacqua, A Di Matteo, et al. (2016) Polymeric microneedles based enzymatic electrodes for electrochemical biosensing of glucose and lactic acid. Sensors and Actuators B: Chemical 236: 343-349.

8. P Dardano, A Caliò, V Di Palma, MF Bevilacqua, A Di Matteo, et al. (2015) A photolithographic approach to polymeric microneedles array fabrication for biomedical applications. Materials 8(12): 8661-8673.

9. P Dardano, A Caliò, J Politi, I Rea, I Rendina, et al. (2016) Optically monitored drug delivery patch based on porous silicon and polymer microneedles. Biomed Opt Express 7(5): 1645-1655.

10. Shabir Q, Webb K, Nadarassan DK, Loni A, Canham LT, et al. (2018) Quantification and reduction of the residual chemical reactivity of passivated biodegradable porous silicon for drug delivery applications. Silicon 10(2): 349.

11. Hawkey PM, Warren RE, Livermore DM, McNulty CA, Enoch DA, et al. (2018) Treatment of infections caused by multidrug-resistant Gramnegative bacteria: report of the British Society for Antimicrobial Chemotherapy/healthcare Infection Society/British Infection Association Joint Working Party. Journal of Antimicrobial Chemotherapy 73(suppl_3): 2-78.

12. Palmieri Gianna, Tatè Rosarita, Gogliettino Marta, Balestrieri Marco, Rea Ilaria, et al. (2018) Small Synthetic Peptides Bioconjugated to Hybrid Gold Nanoparticles Destroy Potentially Deadly Bacteria in Submicromolar Concentration. Bioconjugate Chem 29 (11): 3877-3885.

13. Bruna Agrillo, Marco Balestrieri, Marta Gogliettino, Gianna Palmieri, Rosalba Moretta, et al. (2019) Functionalized polymeric materials with bio-derived antimicrobial peptides for "active" packaging. Int J Mol Sci 20(3): 601 .

14. Palmieri G, Balestrieri M, Proroga YT, Falcigno L, Facchiano A, et al. (2016) New antimicrobial peptides against foodborne pathogens: From in silico design to experimental evidence. Food chemistry 211: 546-554.

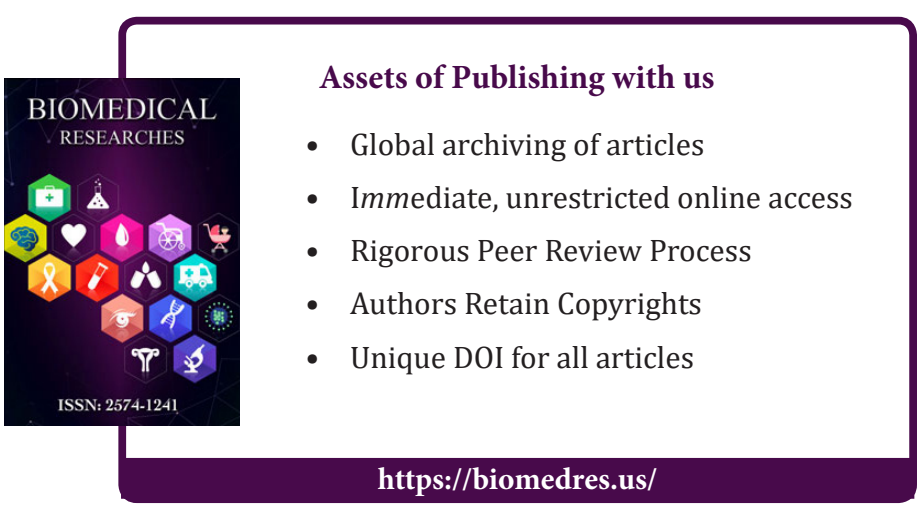

Copyright@ Luca De Stefano| Biomed J Sci \& Tech Res| BJSTR. MS.ID.002585. 